\title{
COMPARATIVE STUDIES ON FORMABILITY ANALYSIS IN METAL FORMING
}

\author{
U.V.Mangudkar ${ }^{1}$, S.P.Mankani ${ }^{2}$ \\ ${ }^{1} P G$ Student, WIT,Solapur, Maharashtra \\ ${ }^{2}$ Professor of Mechanical Engineering WIT,Solapur
}

\begin{abstract}
Sheet metal products are one of the most important semi-finished products used in the steel industry, and metal forming technology is therefore an important engineering domain. The development of new sheet metal forming processes, tooling and so on, has until now, to a large extent been based on experience, rules of thumb and trial-error experiments without or with only little use of scientifically based engineering methods. As mentioned above, experience is not enough, and trial-error experiments are expensive with regard to both money and time. The forming limit diagram (FLD) shows metal formability in metal forming with less cost. . The forming limit diagram typically represents the maximum permissible range of major and minor strains that a typical sheet material can undertake without failure. The forming limit diagram is experimentally measured for each sheet material by placing a grid of circle on the sheet sample and then deforming the same. A comparison of the original and the extensions in the marked grids on the sheet sample provide an estimate of the major and minor strain of the sample. This paper presents a case study of automotive component spring seat. By placing the grid of circles on the component and by measuring the dimensions of deformed circles a forming limit diagram has drawn. The simulations were carried out by fast form advanced software. The results achieved concluded that, safe forming zone is of bottom part and wrinkling tendency is present on side wall of component.
\end{abstract}

Keywords: Forming, Forming limit diagram, Major strain, Minor strain, Safe zone, wrinkling.

\section{INTRODUCTION}

The forming of metals into desired shapes is almost the oldest fabricating technique. Metal forming is an economical method of manufacturing components because loss of material is too less. It is a process in which the desired shapes and size of components are obtained through the plastic deformation of metal. Sheet metals are widely used for industrial and consumer parts because of its capacity for being bent and formed into intricate shapes. Sheet metal parts comprise a large fraction of automotive, agricultural machinery, and aircraft components as well as consumer appliances.

\section{FORMING PROCESSES}

A numbers of sheet metal forming processes are available such as

$$
\begin{aligned}
& \text { Shearing } \\
& \text { Bending } \\
& \text { Deep Drawing } \\
& \text { Stretch forming } \\
& \text { Stretch drawing } \\
& \text { Press forming } \\
& \text { Hydroforming }
\end{aligned}
$$

Each process is used for specific purpose and the requisite shape of the final product.

\subsection{Deep Drawing}

Deep drawing is a sheet metal forming process in which a sheet metal blank is radially drawn into a forming die by the mechanical action of a punch. It is thus a shape transformation process with material retention. The process is considered "deep" drawing when the depth of the drawn part exceeds its diameter. This can be achieved by redrawing the part through a series of dies.

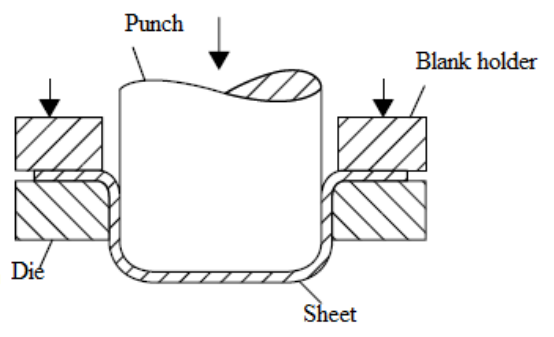

Fig 1: Tooling for deep drawing

\section{DEFECTS FOR DEEP DRAWING PROCESS}

The deep drawing process is applied with the intention of manufacturing a product with a desired shape and no failures. The tools, the blank and the process parameters define deep drawing final product shape. An incorrect design of the tools 
and blank shape or an incorrect choice of material and process parameters can yield a product with a deviating shape or with failures. In the deep drawing the most common defects are presented in figure 2 . In figure 2 , the notations are: 1.flange undulation; 2.side undulation; 3.piece wrinkling; 4.circular traces; 5.scratches; 6.orange peel; 7.Luders bands; 8.cracking of piece flange or piece bottom; 9.edges cracking; 10.misalignment; 11.Contour misalignment; 12.Festoons; 13.delaminations; 14.edge festoons .

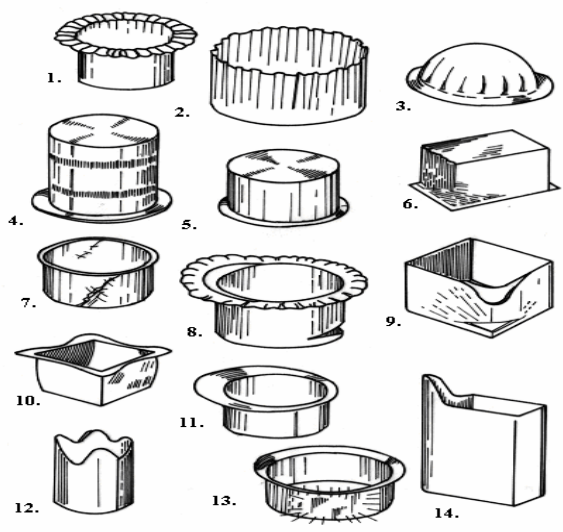

Fig.2: Defects in deep drawing

\section{EXPERIMENTAL ANALYSIS}

\subsection{Introduction}

The forming limit diagram (FLD) (Fig3) gives an indication whether the material can sustain certain ratio of strains without failing is of great help. Keeler [1] pioneered the application of forming limit diagrams (FLD) for accessing the formability of sheet metal.

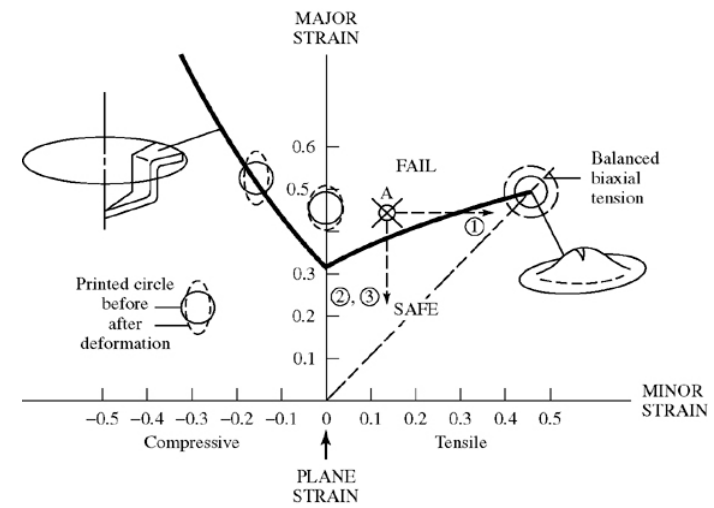

Fig-3: Forming limit diagram

Many researchers have tried to determine the FLD diagrams for different sheet metals commonly used in forming operations either experimentally or theoretically. The experimental method consists of printing a grid pattern of circles of appropriate diameter (generally $2 \mathrm{~mm}$ to $4 \mathrm{~mm}$ ) on the surface of sheet. The sheet is deformed as required but in stages. After each stage the grid pattern is examined.The advantage of printing circular grids is that during the deformation the circles will get deformed into ellipse with major and minor axes directed along the principal directions of strain. The measurement of the axes and knowing the original diameter we can determine principal strains and their directions. As the forming progresses, at some region neck formation may occur. The ratio of strains is determined at the region. This is a point on FLD diagram or curve which separates the safe and unsafe region.An automotive component spring seat is selected for study. The component is shown in fig.4. Material properties are shown in table 3
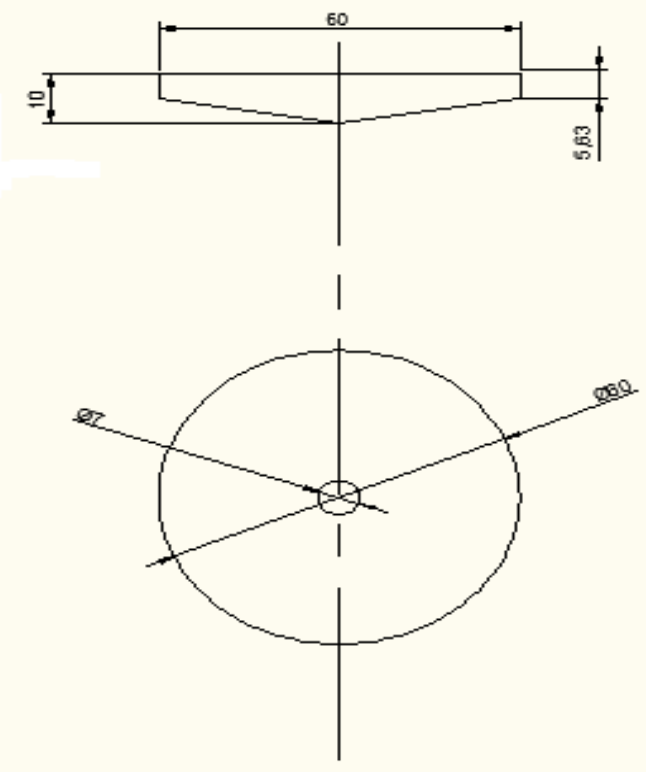

Fig-4: Component dimension

Table 1 Material properties

Material: SS 4010

\begin{tabular}{|l|l|l|}
\hline Sr.No. & Mechanical properties & Value \\
\hline i & Weight & 28 grams \\
\hline ii & Thickness & $0.8 \mathrm{~mm}$ \\
\hline iii & Yield strength & $192 \mathrm{MPa}$ \\
\hline iv & Ultimate tensile strength & $315 \mathrm{MPa}$ \\
\hline
\end{tabular}

\subsection{Formability Analysis of Components under Study}

\subsubsection{Procedure}

1. Take the blank of material.

2. The blank diameter is $70 \mathrm{~mm}$ and thickness of $0.8 \mathrm{~mm}$.

3. Clean the blank with soft cloth. 
4. Draw the circles of constant diameter $(4 \mathrm{~mm})$ with circular array.

5. Set the die of required component.

6. Select the punch force and the stroke required for drawing component.

7. Draw the circular blank with the help of drawing machine.

8. See whether the circular marking is neat visible.

9. Measure the changed dimensions i.e. Major dia. and Minor dia. of each circle after drawing.

10. Calculate the true strains i.e. Major strains and Minor strains of each reading of measurement.

12. Tabulate all the data as per result table. The result table is shown in table 2.

13. Plot the forming limit diagram from the strains calculated.

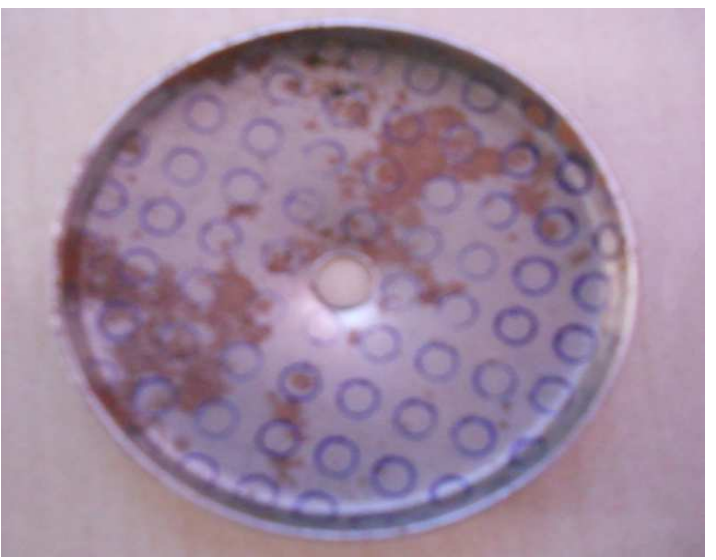

Fig-5: Component with grid

Table 2

\begin{tabular}{|l|l|l|l|l|l|}
\hline $\begin{array}{l}\text { Ellip } \\
\text { se } \\
\text { No. }\end{array}$ & $\begin{array}{l}\text { Major } \\
\text { diamet } \\
\text { er } \\
(\mathrm{mm})\end{array}$ & $\begin{array}{l}\text { Minor } \\
\text { diamet } \\
\text { er } \\
(\mathrm{mm})\end{array}$ & $\begin{array}{l}\text { Original } \\
\text { circle grid } \\
\text { diameter(m } \\
\mathrm{m})\end{array}$ & $\begin{array}{l}\text { Max.Str } \\
\text { ain } \\
(\%)\end{array}$ & $\begin{array}{l}\text { Min.Str } \\
\text { ain } \\
(\%)\end{array}$ \\
\hline 1 & 4.1 & 3.7 & 4 & 2.5 & -7.5 \\
\hline 2 & 4.1 & 3.8 & 4 & 2.5 & -5 \\
\hline 3 & 4.1 & 3.5 & 4 & 2.5 & -12.5 \\
\hline 4 & 4.2 & 3.9 & 4 & 5 & -2.5 \\
\hline 5 & 4.36 & 3.9 & 4 & 9 & -2.5 \\
\hline 6 & 4.1 & 3.54 & 4 & 2.5 & -11.5 \\
\hline 7 & 4.24 & 3.98 & 4 & 6 & -0.5 \\
\hline 8 & 4.2 & 3.92 & 4 & 5 & -2 \\
\hline 9 & 4.3 & 3.92 & 4 & 7.5 & -2 \\
\hline 10 & 4.36 & 3.9 & 4 & 9 & -2.5 \\
\hline 11 & 4.3 & 4 & 4 & 7.5 & 0 \\
\hline 12 & 4.24 & 4 & 4 & 6 & 0 \\
\hline 13 & 4.3 & 3.9 & 4 & 7.5 & -2.5 \\
\hline 14 & 4.28 & 3.9 & 4 & 7 & -2.5 \\
\hline 15 & 4.22 & 3.9 & 4 & 5.5 & -2.5 \\
\hline 16 & 4.3 & 3.9 & 4 & 7.5 & -2.5 \\
\hline 17 & 4.3 & 3.5 & 4 & 7.5 & -12.5 \\
\hline & & & & & \\
\hline
\end{tabular}

\begin{tabular}{|c|c|c|c|c|c|}
\hline 18 & 4.3 & 4.2 & 4 & 7.5 & -2.5 \\
\hline 19 & 4.3 & 3.9 & 4 & 7.5 & -12.5 \\
\hline 20 & 4.3 & 3.92 & 4 & 7.5 & -2 \\
\hline 21 & 4.36 & 3.9 & 4 & 9 & -2.5 \\
\hline 22 & 4.3 & 3.5 & 4 & 7.5 & -12.5 \\
\hline 23 & 4.22 & 3.9 & 4 & 5.5 & -2.5 \\
\hline 24 & 4.3 & 3.9 & 4 & 7.5 & -2.5 \\
\hline 25 & 4.3 & 3.92 & 4 & 7.5 & -2 \\
\hline 26 & 4.3 & 3.5 & 4 & 7.5 & -12.5 \\
\hline 27 & 4.3 & 3.92 & 4 & 7.5 & -2 \\
\hline 28 & 4.36 & 3.9 & 4 & 9 & -2.5 \\
\hline 29 & 4.3 & 3.92 & 4 & 7.5 & -2 \\
\hline 30 & 4.2 & 3.92 & 4 & 8 & -2 \\
\hline 31 & 4.36 & 3.9 & 4 & 9 & -2.5 \\
\hline 32 & 4.3 & 3.8 & 4 & 7.5 & -5 \\
\hline 33 & 4.16 & 3.56 & 4 & 4 & -11 \\
\hline 34 & 4.1 & 3.78 & 4 & 2.5 & -5.5 \\
\hline 35 & 4.2 & 3.92 & 4 & 8 & -2 \\
\hline 36 & 4.1 & 3.78 & 4 & 2.5 & -5.5 \\
\hline 37 & 4.36 & 3.9 & 4 & 9 & -2.5 \\
\hline 38 & 4.36 & 3.9 & 4 & 9 & -2.5 \\
\hline 39 & 4.1 & 3.9 & 4 & 2.5 & -2.5 \\
\hline 40 & 4.2 & 3.92 & 4 & 8 & -2 \\
\hline 41 & 4.36 & 3.9 & 4 & 9 & -2.5 \\
\hline 42 & 4.3 & 3.8 & 4 & 7.5 & -5 \\
\hline 43 & 4.16 & 3.56 & 4 & 4 & -11 \\
\hline 44 & 4.1 & 3.78 & 4 & 2.5 & -5.5 \\
\hline
\end{tabular}

\subsubsection{FORMING LIMIT DIAGRAM}

Fig.6 shows forming limit diagram for above results.

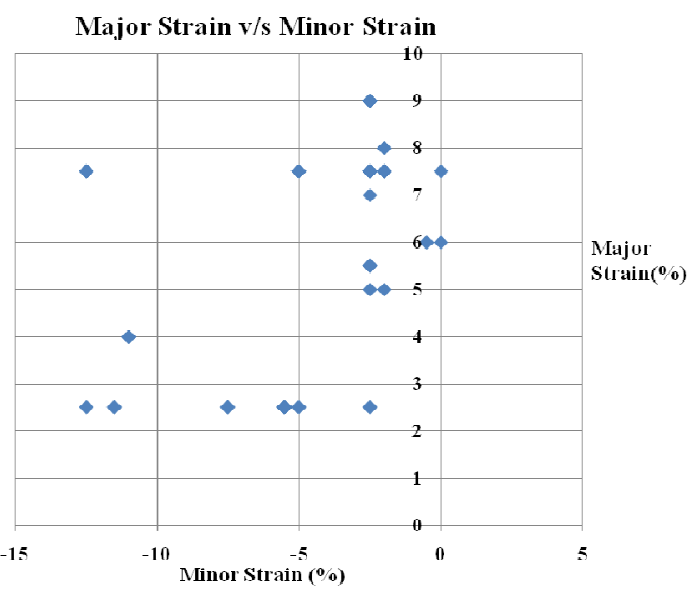

Fig-6: Forming limit diagram for component

\section{SIMULATION}

Fast form advanced is finite element analysis simulation software. It is used for formability analysis and cost optimization of sheet metal component. 


\subsection{Solution by Simulation}

The result of above component by simulation is as follows:-

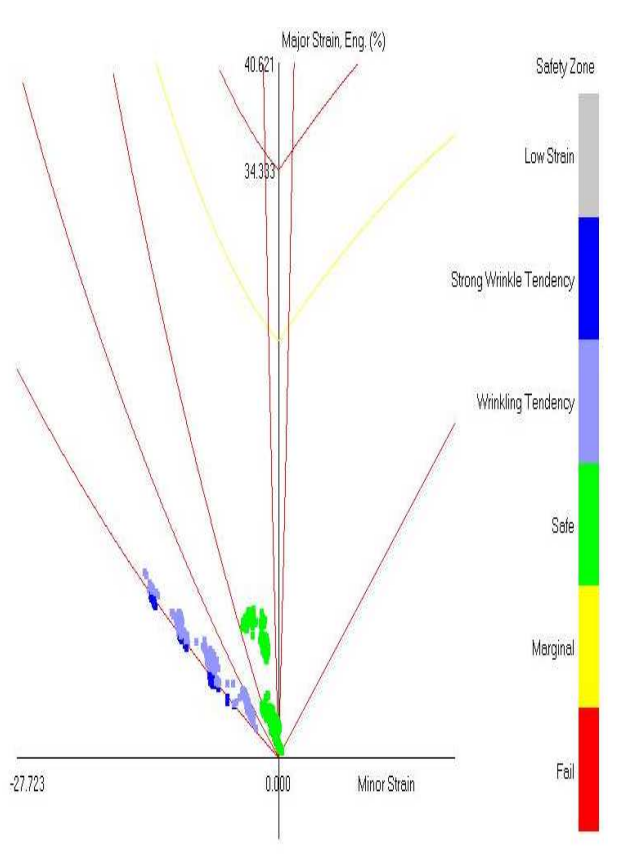

Fig-7: Forming limit diagram

Fig.8: shows a maximum safe point whose coordinates are 2.786 and 8.673

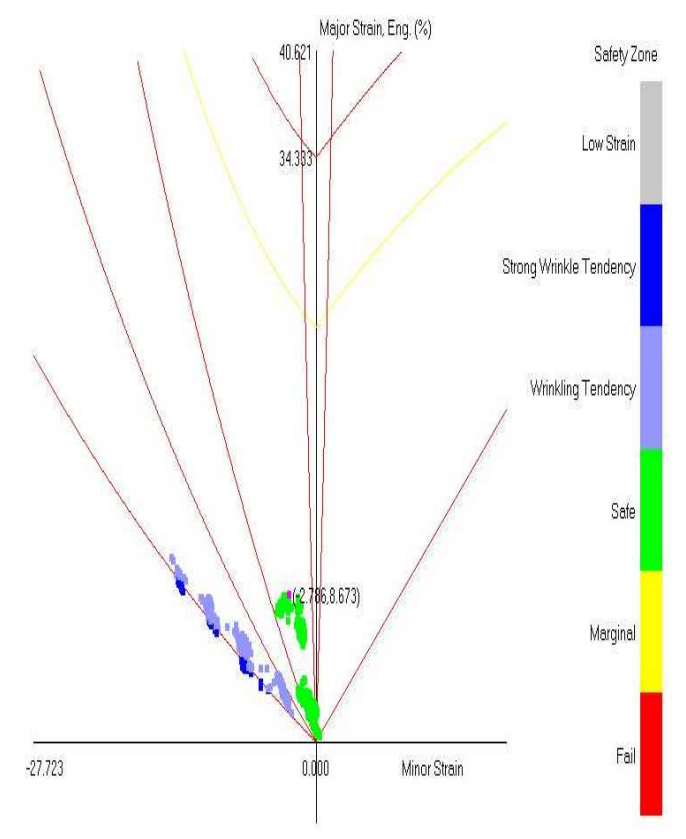

Fig-8:- Forming limit diagram with safe point
Fig 9 shows a wrinkling tendency point whose coordinates are -14.774 and 10.802 .

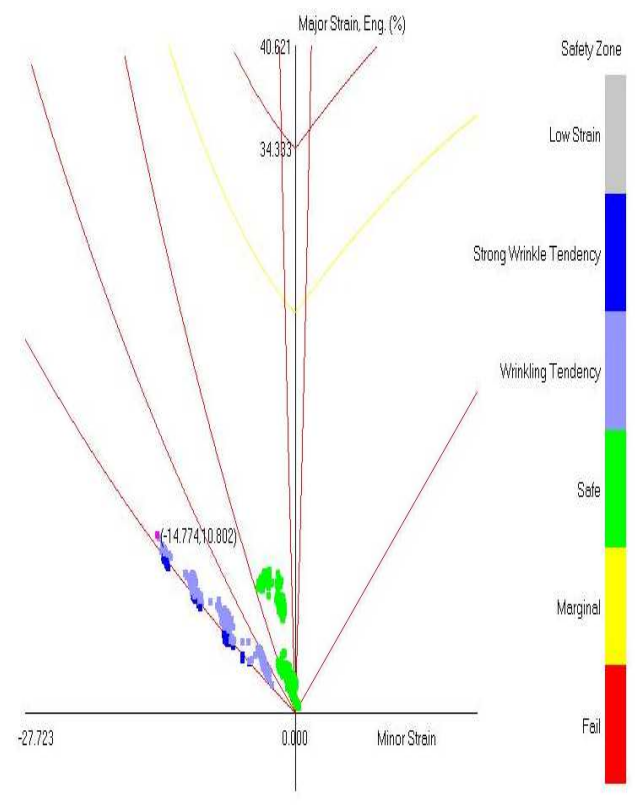

Fig-9: Forming limit diagram with wrinkling tendency point

\section{CONCLUSIONS}

This study compares the forming limit diagram for component by experimentally and by simulation software. Experimental and numerical results were found to agree closely. Also, it was found that Fast form advanced software is capable of simulating the forming of component fairly accurately. The results of study are summarized below.

1. The safe point obtained by experimentally is having maximum minor strain and major strain coordinates -2.5 and 8.9 respectively and that of numerically are -2.786 and 8.673 .

2 . The wrinkling tendency point obtained by experimentally is having minor strain and major strain coordinates -12.5 and 7.5 respectively and that of numerically are -14.774 and 10.802 .

3. The wrinkling tendency present on the side wall.

4. Safe zone present on the bottom part of the component.

5. There were not failing, marginal, strong wrinkling tendency and low strain zones present in the component.

\section{REFERENCES}

[1]. Keeler, S.P.; Sheet Met.Indust.,Vol.42. p.683,1965

[2].Dr.WaleedK.Jawad,JamalH.Mohamed, "Studying the Effect of Punch Nose Radius on Deep Drawing Operation" Eng.\&Tech.Vol.26.No.,pp55-73(2008)

[3]. G. Venkateswarlu, M. J. Davidson and G. R. N. Tagore, "Influence of process parameters on the cup drawing of aluminium 7075 sheet" International Journal of Engineering, Science and Technology Vol. 2, No. 11, pp. 41-49(2010) 
[4]. Y. Marumo, H. Saiki, L Ruan , "Effect of sheet thickness on deep drawing of metal foils" Journal of Achievements in Materials and Manufacturing Engineering Vol.20 Issues 1-2 (2007)

[5].M. Ahmetoglu, T. R. Broek, G. Kinzel, T. Altan, "Control of Blank Holder Force to Eliminate Wrinkling and Fracture in Deep-Drawing Rectangular Parts" Annals of the CIRP Vol. $44 / 1 / 1995$

[6]. H. Gharib, A.S. Wifi, M. Younan, A. Nassef, "Optimization of the blank holder forcein cup drawing" Journal of Achievements in Materials and Manufacturing Engineering, Volume 18, ISSUE 1-2 September-October 2006

[7]. W.M. Chan, H.I. Chew, H.P. Lee, B.T. Cheok , "Finite element analysis of spring-back of V-bending sheet metal forming processes" Journal of Materials Processing Technology Vol.148 pp 15-24, (2004)

Books:

[8].Kalpakjain, Manufacturing Processes for Engineering Materials ( Pearson Education, 2007 ) 